\title{
First experiences with HeartMate 3 follow-up and adverse events
}

Jasmin S. Hanke, MD, Günes Dogan, MD, Sebastian V. Rojas, MD, Amelie Zoch, BSc, Christina Feldmann, PhD, Ezin Deniz, MD, Murat Avsar, MD, Gregor Warnecke, MD, PhD, Axel Haverich, MD, PhD, and Jan D. Schmitto, MD, PhD

\section{ABSTRACT}

Background: The novel HeartMate 3 (HM3) left ventricular assist device (LVAD) received its CE mark in October 2015. It is a new compact LVAD featuring fully magnetically levitated pump, artificial pulse, large pump gaps, and a modular driveline. Here, we present outcomes and adverse events of a single-center cohort 6 months after HM3 implantation.

Methods: We retrospectively studied a patient cohort of 27 patients who were supported with the HM3 at a single institution. We excluded patients with biventricular assist devices and other types of assist devices as well as LVAD exchange and re-operative procedures.

Results: Twenty-seven patients were enrolled into the study. Within 1 year after HM3 implantation, 1 patient received a heart transplant and 3 patients died. Thirty-day survival was $88.9 \%$ and 6 months $85.2 \%$. No pump thrombosis and no strokes were observed within 6 months. Right heart failure was diagnosed in 1 patient after HM3 implantation (3.7\%). No technical complications of the pump were documented. No pump exchanges were necessary.

Conclusions: The novel LVAD HM3 has already shown good CE mark trial results. Within this first report after the CE mark trial, the 6-month survival after HM3 implantation was $85.2 \%$. The HM3 showed excellent midterm results with $0 \%$ stroke and $0 \%$ pump thrombosis rates 6 months after implantation. (J Thorac Cardiovasc Surg 2017;154:173-8)

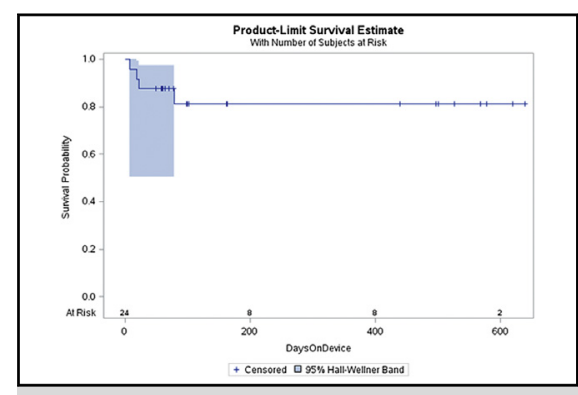

Survival after HM3 implantation.

Central Message

The HM3 showed excellent midterm results with $0 \%$ stroke and $0 \%$ pump thrombosis rates 6 months after implantation. The rates of other complications remained low.

\section{Perspective}

There is a need for new devices with improved technology to reduce adverse events to further increase the acceptance and durability of mechanical support. Here, we present the first experience study on outcomes and complications of a single-center cohort after HeartMate 3 implantation.

See Editorial Commentary page 179
The left ventricular HeartMate II (HMII; St Jude Medical Corporation, St Paul, Minn) is the commercially most successful left ventricular assist device (LVAD), with more than 22,000 implantations worldwide. The overall importance of LVADs is increasing. ${ }^{1}$ The recent technical development has led to numerous improvements as well as a miniaturization process of LVADs. ${ }^{2}$ The novel

\footnotetext{
From the Department of Cardiac, Thoracic, Transplantation, and Vascular Surgery, Hannover Medical School, Hannover, Germany.

Received for publication Sept 15, 2016; revisions received Nov 30, 2016; accepted for publication Jan 17, 2017; available ahead of print March 6, 2017

Reprint requests: Jan D. Schmitto, MD, PhD, Director of the Mechanical Circulatory Support and Cardiac Transplant Program, Department of Cardiac, Thoracic, Transplantation, and Vascular Surgery, Hannover Medical School, Carl-Neuberg-Str, 1 30625 Hannover, Germany (E-mail: Schmitto.Jan@mh-hannover.de). $0022-5223 / \$ 36.00$

Copyright (C) 2017 by The American Association for Thoracic Surgery http://dx.doi.org/10.1016/j.jtcvs.2017.01.045
}

HeartMate 3 (HM3; Thoratec Corporation, Pleasanton, Calif) underwent its first-in-human implant in June 2014 at Hannover Medical School, Hannover, Germany, and received its $\mathrm{CE}$ mark based on its excellent midterm results in October $2015 .^{4}$ It is a new compact LVAD that is associated with several new technical features (eg, fully magnetically levitated pump, artificial pulse, large pump gaps, modular driveline). ${ }^{3}$ These benefits have potential to lead to superior outcomes compared with

Scanning this $\mathrm{QR}$ code will take you to a supplemental video for the article.

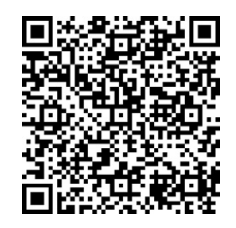




$$
\begin{aligned}
& \text { Abbreviations and Acronyms } \\
& \text { ECC }=\text { extracorporeal circulation } \\
& \text { fHb }=\text { free hemoglobin } \\
& \text { HM3 }=\text { HeartMate } 3 \\
& \text { HMII }=\text { HeartMate II } \\
& \text { LDS }=\text { lactate dehydrogenase } \\
& \text { LVAD }=\text { left ventricular assist device } \\
& \text { PAP }=\text { pulmonary artery pressure } \\
& \text { POD }=\text { postoperative day } \\
& \text { VAD }=\text { ventricular assist device }
\end{aligned}
$$

its predecessor HeartMate II (HM2; Thoratec Corporation, Pleasanton, Calif) and other comparable assist devices.

With increased clinical experience in mechanical support, there have been significant reductions in some adverse events, ${ }^{5,6}$ but further improvements are still needed to reduce complications, such as infection, bleeding, thrombus, and stroke, ${ }^{7-10}$ which remain major concerns in ventricular assist device (VAD) therapy. Consequently, there is a need for new devices with improved technology to reduce adverse events to further increase the acceptance and durability of LVAD support.

In the study, we present 1-year outcomes and complications of a single-center cohort after HM3 implantation.

\section{METHODS \\ Patients}

We retrospectively studied a cohort of 27 patients who were supported with the continuous-flow LVAD HM3 at a single institution between June 2014 and April 2016. Eight of these patients of the study cohort were part of the HM3 CE mark trial in 2014. For the performance of this retrospective study, the database of Hannover Medical School, Hannover, Germany, was queried. All causes of death and adverse events were determined through examination of medical records. Only primary implantations were included in this study. Exclusion criteria were biventricular assist devices and other types of assist devices as well as LVAD exchange and re-operative procedures. All patients underwent HM3 implantation via full sternotomy via conventional technique with outflow graft anastomosis to the ascending aorta (Video 1). No concomitant procedures were performed. Heparin was started 6 hours after surgery. Intravenous heparin was administered as a bridge until anticoagulation with phenprocoumon was in the therapeutic range, with a target international normalized ratio of 2.0 to 3.0 , plus aspirin at $100 \mathrm{mg}$ per day. Blood pressure was measured by Doppler sonography in all patients. Target blood pressure was $60 \mathrm{~mm} \mathrm{Hg}$ (mean).

\footnotetext{
Study Design

The data were retrospectively collected by electronic medical record review. Baseline characteristics were obtained for all patients before HM3 implantation. After HM3 implantation, survival, causes of death, and complications were recorded for all patients. Follow-up was $100 \%$ complete. Minimal follow-up time was 7 months; maximal follow-up time was 28 months. Because this was a retrospective study, the hospital ethical review board waived the need for patient consent to the study.
}

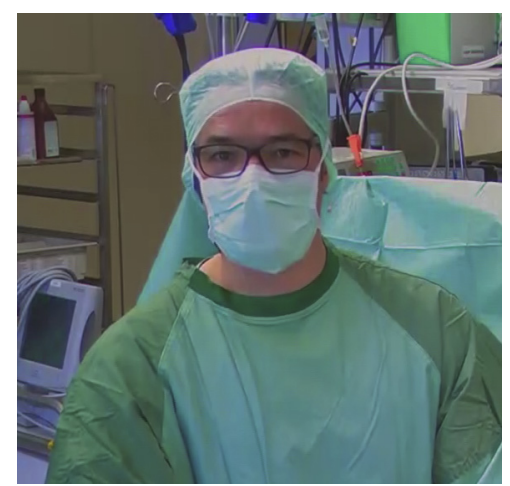

VIDEO 1. HeartMate 3 implantation at Hannover Medical School. Video available at: http://www.jtcvsonline.org/article/S0022-5223(17)30178-2/ addons.

\section{Statistical Methods}

All statistical analyses were performed using SPSS version 22 software (IBM SPSS Statistics; IBM Corporation, Chicago, Ill). Categorical variables are reported in frequencies and continuous variables are reported as mean \pm standard deviation or as median with range if applicable. Complications (adverse events) were recorded and analyzed according to the standard INTERMACS classifications.

\section{RESULTS}

\section{Baseline Characteristics}

This first single-center retrospective study consisted of 27 consecutive patients who received an HM3 device between June 2014 and April 2016 at Hannover Medical School, Hannover, Germany. Other implanted LVADs (eg, HeartMate II, Thoratec; HVAD, HeartWare [Framingham, Mass]; MVAD, HeartWare; HA5, Reliant Heart [Houston, Tex]) and biventricular assist devices as well as LVAD exchanges were excluded from analysis.

Detailed baseline characteristics of the patient cohort can be found in Table 1. In total, 23.4 patient years (284.5 months; 8544 days) were analyzed.

Average time on cardiopulmonary bypass was $86.6 \pm 45.0$ minutes. Average erythrocytes concentrate application until discharge was $5.1 \pm 4.7$.

Preoperatively, 1 patient was supported by Impella (ABIOMED, Inc, Danvers, Mass) due to a fulminant myocardial infarction. No patients were preoperatively supported by extracorporeal membrane oxygenation or intraaortic balloon pump. The most common preoperative risk factor was pulmonary hypertension (PAP mean greater than $25 \mathrm{~mm} \mathrm{Hg}$ ) (22.4\%). Four (14.8\%) patients were diagnosed with type 2 diabetes. Four $(14.8 \%)$ patients had a myocardial infarction within the past 90 days before LVAD implantation.

\section{Outcomes After HM3 Implantation}

The Kaplan-Meier curves in Figure 1 illustrate the patient survival. Fifteen days after HM3 implantation, a survival of 
TABLE 1. Baseline characteristics of the study group

\begin{tabular}{|c|c|}
\hline & HeartMate 3 patients \\
\hline Total & 27 \\
\hline Male, $n(\%)$ & $25(92.6)$ \\
\hline Female & $2(7.4)$ \\
\hline Average age male (y) & $56.2 \pm 10.8$ \\
\hline Average age female (y) & $63 \pm 4.2$ \\
\hline Average body mass index $\left(\mathrm{kg} / \mathrm{m}^{2}\right)$ & 27.95 \\
\hline \multicolumn{2}{|l|}{ Diagnoses, n (\%) } \\
\hline Dilated cardiomyopathy & $18(66.7)$ \\
\hline Ischemic cardiomyopathy & $9(33.3)$ \\
\hline \multicolumn{2}{|l|}{ NYHA profile, $\mathrm{n}(\%)$} \\
\hline IV & $26(96.3)$ \\
\hline III & $1(3.7)$ \\
\hline \multicolumn{2}{|l|}{ INTERMACS profile, $\mathrm{n}(\%)$} \\
\hline I & $1(3.7)$ \\
\hline II & $2(7.4)$ \\
\hline III & $23(85.2)$ \\
\hline IV & $1(3.7)$ \\
\hline \multicolumn{2}{|l|}{ Stay } \\
\hline $\begin{array}{l}\text { Average in-hospital stay after } \\
\text { LVAD implantation (d) }\end{array}$ & $21.9 \pm 9.4$ \\
\hline Average ICU stay (d) & $3.6 \pm 2.7$ \\
\hline $\begin{array}{l}\text { Average cardiopulmonary bypass } \\
\text { time (min) }\end{array}$ & $86.6 \pm 45.0$ \\
\hline $\begin{array}{l}\text { Average erythrocyte concentrate until } \\
\text { discharge }\end{array}$ & $5.1 \pm 4.7$ \\
\hline \multicolumn{2}{|l|}{ Preoperative right heart catheter } \\
\hline \multicolumn{2}{|l|}{ Average right atrial pressure $(\mathrm{mm} \mathrm{Hg})$} \\
\hline Systolic & $13.3 \pm 2.8$ \\
\hline Diastolic & $12.2 \pm 3.9$ \\
\hline Mean & $11.3 \pm 2.5$ \\
\hline \multicolumn{2}{|c|}{ Average pulmonary artery pressure $(\mathrm{mm} \mathrm{Hg})$} \\
\hline Systolic & $52.3 \pm 23.2$ \\
\hline Diastolic & $23.9 \pm 10.4$ \\
\hline Mean & $34.8 \pm 15.3$ \\
\hline $\begin{array}{l}\text { Average pre-implant cardiac index } \\
\left(\mathrm{L} / \mathrm{min} / \mathrm{m}^{2}\right)\end{array}$ & $1.9 \pm 0.4$ \\
\hline \multicolumn{2}{|l|}{ Echocardiography } \\
\hline $\begin{array}{l}\text { Average preoperative LV ejection } \\
\text { fraction (Echo) }\end{array}$ & $24.3 \pm 11.1$ \\
\hline $\begin{array}{l}\text { Average pre-discharge LV ejection } \\
\text { fraction (Catheter) }\end{array}$ & $19.1 \pm 7.3$ \\
\hline $\begin{array}{l}\text { Average pre-operative LV end } \\
\text { diastolic diameter }\end{array}$ & $75.9 \pm 11.1$ \\
\hline $\begin{array}{l}\text { Average pre-discharge LV end } \\
\text { diastolic diameter }\end{array}$ & $64.5 \pm 13.2$ \\
\hline \multicolumn{2}{|c|}{ Preoperative mitral valve insufficiency, $\mathrm{n}(\%)$} \\
\hline 0 & $9(33.3)$ \\
\hline I & $12(44.4)$ \\
\hline II & $4(14.8)$ \\
\hline II-III & $1(3.7)$ \\
\hline \multicolumn{2}{|c|}{ Preoperative tricuspid valve insufficiency, n (\%) } \\
\hline 0 & $6(22.2)$ \\
\hline I & $9(33.3)$ \\
\hline II & $8(29.6)$ \\
\hline III & $4(14.8)$ \\
\hline
\end{tabular}

TABLE 1. Continued

\begin{tabular}{ll}
\hline & HeartMate 3 patients \\
\hline Status, $\mathrm{n}(\%)$ & $1(3.7)$ \\
Cardiac transplantation & $0(0)$ \\
LVAD explantation due to recovery & $3(11.1)$ \\
Death after LVAD implantation & NYHA, New York Heart Association; $L V A D$, left ventricular assist device; $I C U$, inten- \\
sive care unit; $L V$, left ventricular.
\end{tabular}
sive care unit; $L V$, left ventricular.

$96.3 \%(26 / 27)$ was observed in the study cohort. After 30 days, the survival rate was $88.9 \%, 88.9 \%$ after 3 months, and $85.2 \% 6$ months after HM3 implantation.

Of 27 patients, after a period of 6 months, 1 patient had successfully undergone heart transplantation on postoperative day (POD) 51. Three patients died during the study period. The remaining 23 patients are still ongoing on the device. Six-month survival after HM3 implantation is $85.2 \%$.

The longest ongoing patient out of the HM3 study has been on device for more than 2 years as of November 15 , 2016.

Pre- and postoperative laboratory values are listed in Table 2. Renal as well as liver laboratory parameters improved significantly after VAD implantation (Table 2).

\section{Causes of Death}

Six months after HM3 implantation, of 27 patients, 3 patients had died. The first patient died on POD 17 because of pneumonic sepsis. The second and the third patients died on POD 7 and POD 22 due to multiorgan failure. Right heart failure was diagnosed in the second patient.

\section{Complications}

Thirty days after HM3 implantation. Adverse events are listed in Table 3. The most common complication during the first 30 days was non-LVAD-associated infection, with 8 events in $7(25.9 \%)$ patients of the study group.

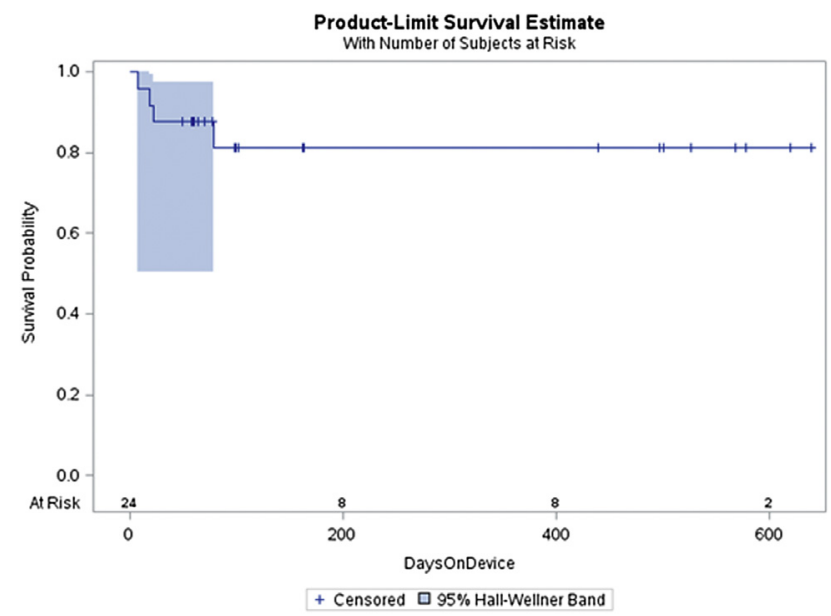

FIGURE 1. Kaplan-Meyer survival curves for the study group. 
TABLE 2. Pre- and postoperative laboratory parameter of the study group

\begin{tabular}{lccc}
\hline & Preoperative & $\begin{array}{c}\text { Postoperative/ } \\
\text { pre-discharge }\end{array}$ & $\boldsymbol{P}$ \\
\hline SAST, U/L & $82.3 \pm 128.3$ & $32.9 \pm 26.3$ & .037 \\
SALT, U/L & $110.8 \pm 229.6$ & $38.0 \pm 52.4$ & .035 \\
GLDH, U/L & $23.0 \pm 86.7$ & $3.5 \pm 5.0$ & .002 \\
SCHE, U/L & $7.3 \pm 2.4$ & $5.1 \pm 1.7$ & .015 \\
Total bilirubin, $\mu \mathrm{mol} / \mathrm{L}$ & $36.8 \pm 80.7$ & $32.4 \pm 66.6$ & .111 \\
Creatinine, $\mu \mathrm{mol} / \mathrm{L}$ & $122.6 \pm 44.6$ & $95.9 \pm 36.7$ & .008 \\
Urea, mmol/L & $8.9 \pm 4.3$ & $7.2 \pm 5.6$ & .017 \\
eGFR, $\mathrm{mL} / \mathrm{min}$ & $56.1 \pm 19.8$ & $63.8 \pm 16.1$ & .123 \\
Sodium, $\mathrm{mmol} / \mathrm{L}$ & $139.1 \pm 3.0$ & $137.0 \pm 3.6$ & .168 \\
C-reactive protein, $\mathrm{mg} / \mathrm{dL}$ & $33.1 \pm 51.4$ & $75.4 \pm 85.7$ & .004 \\
\hline SAST, S &
\end{tabular}

$S A S T$, Serum aspartate aminotransferase; SALT, serum alanine aminotransferase; $G L D H$, glutamate dehydrogenase; $S C H E$, serum cholinesterase.

LVAD-related infections were observed in $2(8.3 \%)$ patients.

Eight minor bleeding events were documented in 6 patients $(22.2 \%)$ during the first month after HM3 implantation. Of those, 1 patient suffered gastrointestinal bleeding $(3.7 \%)$ and 5 patients suffered minor bleeding, such as epistaxis. None of these bleeding events required surgical intervention. One patient underwent re-sternotomy 3 weeks after HM3 implantation due to a late cardiac tamponade.

No cases of pump thrombosis or stroke were observed. Right heart failure was observed in 1 patient $(3.7 \%)$. There were no technical failures of the pump.

Six months after HM3 implantation. Of 27 patients, 24 reached the 6-month mark of this study. Six months after HM3 implantation, a total of 12 bleeding events in 8 patients were observed. Of those, 1 required surgery $(3.7 \%)$ due to late cardiac tamponade $(0.0035112$ events per patient month). One case of gastrointestinal bleeding was observed $(3.7 \%)(0.0035112$ events per patient month).
No pump thrombosis and no strokes were witnessed in the study group during 6 months of HM3 support.

Six LVAD-related infections were documented in 4 patients $(14.8 \%)(0.0210675$ events per patient month). Three patients died in the first 3 weeks; the adjusted rate is $16.6 \%$. All of the documented infections were driveline related. Eight non-LVAD-related infections were documented in 7 patients $(33.3 \%)$ during the first year after HM3 implantation (0.0280899 events per patient month).

Right heart failure was diagnosed in 1 patient during the early postoperative course after HM3 implantation (3.7\%) (0.0070224 events per patient month). No technical complications of the pump were documented. There were no pump exchanges.

\section{Lactate Dehydrogenase and Free Hemoglobin}

The average lactate dehydrogenase (LDH, U/L) as well as free hemoglobin ( $\mathrm{fHb}, \mathrm{mg} / \mathrm{L}$ ) laboratory values are displayed in Figure 2. The fHb curve shows a steep decline followed by a slight increase in the sixth postoperative month. After the sixth month, the curve is decreasing to normal values. LDH levels showed a decrease during the whole study period, with an average $\mathrm{LDH}$ value of 266.5 $\mathrm{U} / \mathrm{L}$ after 6 months of HM3 support and an average $\mathrm{fHb}$ of $158.8 \mathrm{mg} / \mathrm{L}$.

\section{DISCUSSION}

Heart transplantation remains the gold standard for eligible patients in the therapy of terminal heart failure even though it might not be available to everyone. Yet, the improvements of the new-generation pumps are promising and are likely to successfully close the gap between the lack of organ donors and patients on the transplant list.

In this study, 6-months outcomes after HM3 implantation are presented. One-year survival in this group of patients was $85.2 \%$. The HM3 CE mark trial had shown a

TABLE 3. Adverse events in the study group

\begin{tabular}{|c|c|c|c|c|c|c|c|c|c|c|c|}
\hline & \multicolumn{2}{|c|}{$\begin{array}{c}1 \text { Month } \\
\mathbf{n}=\mathbf{2 7} \\
\end{array}$} & \multicolumn{2}{|c|}{$\begin{array}{c}3 \text { Months } \\
\mathrm{n}=\mathbf{2 4} \\
\end{array}$} & \multicolumn{2}{|c|}{$\begin{array}{c}6 \text { Months } \\
n=23\end{array}$} & \multicolumn{2}{|c|}{$\begin{array}{c}>6 \text { Months } \\
n=23 \\
\end{array}$} & \multicolumn{2}{|c|}{$\begin{array}{c}\text { All (1 y) } \\
\mathbf{n}=\mathbf{2 7}\end{array}$} & \multirow{2}{*}{$\begin{array}{c}\text { Events per } \\
\text { patient month }\end{array}$} \\
\hline & Patients & Events & Patients & Events & Patients & Events & Patients & Events & Patients & Events & \\
\hline \multicolumn{12}{|l|}{ Bleeding } \\
\hline Bleeding event & $6(22.2)$ & 8 & $3(12.5)$ & 3 & $0(0)$ & 0 & $1(4.3)$ & 1 & $8(33.3)$ & 12 & 0.0421347 \\
\hline Requiring surgery & $1(4.2)$ & 0 & $0(0)$ & 1 & $0(0)$ & 0 & $0(0)$ & 0 & $1(3.7)$ & 1 & 0.0035112 \\
\hline GI bleeding & $1(3.7)$ & 1 & $0(0)$ & 0 & $0(0)$ & 0 & $0(0)$ & 0 & $1(3.7)$ & 1 & 0.0035112 \\
\hline Pump thrombosis & $0(0)$ & 0 & $0(0)$ & 0 & $0(0)$ & 0 & $0(0)$ & 0 & $0(0)$ & 0 & 0 \\
\hline Technical complication & $0(0.0)$ & 0 & $0(0)$ & 0 & $0(0)$ & 0 & $0(0)$ & 1 & $0(0)$ & 0 & 0 \\
\hline \multicolumn{12}{|l|}{ Infection } \\
\hline LVAD-related & $2(8.3)$ & 2 & $1(4.2)$ & 2 & $0(0)$ & 0 & $2(8.7)$ & 2 & $4(14.8)$ & 6 & 0.0210675 \\
\hline Non-LVAD-related & $7(25.9)$ & 8 & $0(0)$ & 0 & $0(0)$ & 0 & $0(0)$ & 0 & $7(25.9)$ & 8 & 0.0280899 \\
\hline Right heart failure & $1(3.7)$ & 1 & $1(4.8)$ & 1 & $0(0)$ & 0 & $0(0)$ & 0 & $1(3.7)$ & 1 & 0.0035112 \\
\hline Stroke & $0(0)$ & 0 & $0(0)$ & 0 & $0(0)$ & 0 & $0(0)$ & 0 & $0(0)$ & 0 & 0 \\
\hline
\end{tabular}

GI, Gastrointestinal; $L V A D$, left ventricular assist device. 


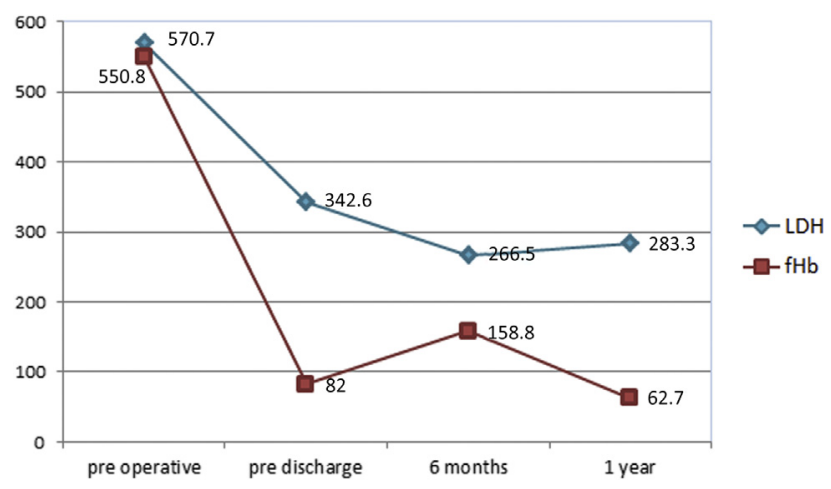

FIGURE 2. Lactate dehydrogenase (LDH [U/L]) and free hemoglobin (fHb $[\mathrm{mg} / \mathrm{L}]$ ) levels after HM3 implantation.

6-month survival of $92.0 \%$ and the MOMENTUM trial showed a 6-month survival of $86.2 \%$ in the study group. ${ }^{4,11}$ Reported key adverse events included reoperation for bleeding (14\%), driveline infection (10\%), gastrointestinal bleeding $(8 \%)$, and debilitating stroke $(8 \%)$ in the nonrandomized Conformité Européene study. ${ }^{4}$ The US-based MOMENTUM trial reported rates of $9.9 \%$ for bleeding requiring surgery, $15.9 \%$ for gastrointestinal bleeding, $11.9 \%$ driveline infection, $0 \%$ pump thrombosis, and a stroke rate of $7.9 \% .^{11}$ In our singlecenter cohort, 1 year after HM3 implantation there was 1 reoperation for bleeding $(4.2 \%), 17 \%$ LVAD-related infections, $4 \%$ gastrointestinal bleedings, no strokes $(0 \%)$, and no device failures $(0 \%)$ in the first 6 months after implantation.

LVAD pump thrombosis has been extensively discussed in the past years. For HMII, Starling et $\mathrm{al}^{12}$ reported that pump exchange or death due to pump thrombosis increased during 2011 and 2012, but the level of the increase remained small. ${ }^{10,13,14}$ A risk factor analysis suggested that a number of patient-related factors contribute to the risk of thrombosis. ${ }^{12}$ Although other centers reported increased thrombosis rates, we reported a steady rate of $2.2 \%{ }^{13}$ Smedira et $\mathrm{al}^{14}$ analyzed a total of 995 thrombosed pumps and also reported an increase in pump thrombosis in 2010, which reached a maximum in 2012, and then plateaued at a level that was reportedly 3 times higher than pre-2010. In our study cohort, we did not observe cases of pump thrombosis. In accordance with our results, the CE mark study as well as the MOMENTUM trial also reported no pump thrombosis, respectively. ${ }^{4,11}$ Debilitating strokes were reported in $8 \%$ of the patients in the CE mark study and in $7.9 \%$ of the patients in the MOMENTUM trial. ${ }^{4,11}$ In our patient population, even 1 year after HM3 implantation, no strokes were observed.

Compared with the HMII, one of the distinctive features of the HM3 is its fully magnetically levitated (Mag-Lev) rotor, which eliminates the need for mechanical bearings or hydrodynamic blood bearings. There are large secondary flow path gaps of $0.5 \mathrm{~mm}$ along the side of the rotor, and $1.0 \mathrm{~mm}$ above and below the rotor, which are 10 to 20 times that of other devices being used. ${ }^{3}$ In addition, the pump is capable of automatic speed modifications (reduction and increase of rotor speed every 2 seconds), creating a wash-out cycle as well as an "artificial pulse." These features might lead to the reduction of complications, such as pump thrombosis and strokes. Yet, larger studies need to reconfirm the favorable outcomes of patients with the HM3. Nevertheless, the results of the studies are promising.

One of the major disadvantages of the HeartMate II compared with other available assist devices (eg, HeartWare HVAD) is the large pump housing and therefore the limited possibilities of less-invasive implantations. With the reduced size of its pump housing, minimally invasive implantation strategies become available using the HM3. Minimally invasive cardio-surgical procedures are anticipated to carry some positive effects (eg, reduction of trauma, blood loss, and infections; decrease in intensive care unit and in-hospital stays; and improved overall outcomes). ${ }^{2,15-22}$ The new developments and implantation techniques of LVADs could contribute to the improvement of therapy outcomes by reducing important operative complication rates, such as right ventricular failure by avoiding pericardial opening. ${ }^{16}$ Because the miniaturization process of LVADs is ongoing, minimally invasive procedures might gain importance; however, major comparative trials between conventional and less-invasive procedures have not yet been published.

Compared with its predecessor HeartMate II, the HM3 seems to be associated with superior short- and midterm outcomes and a reduction of adverse events. ${ }^{4}$ Additionally, based on lower power consumption, it has longer battery capacity, which improves quality of life of patients with a VAD. In case of severe device infection or pump thrombosis, LVAD exchange procedures are an opportunity to upgrade patients to a new-generation pump that offers, for example, advanced reduction of adverse events or longer battery hours. ${ }^{23-26}$ Our group previously reported the first case of LVAD upgrade from HeartMate II to HeartMate 3.

Studies to investigate the potential of less-invasive implantation techniques as well as studies on outcomes of upgrades from HMII to HM3 are needed to prove the benefits of these strategies. Enrollment for the HM3 less-invasive implantation trial, as well as a study on LVAD upgrades, started in 2015 and is currently ongoing.

\section{Limitations}

This study has several limitations. The data are retrospectively collected and analyzed and therefore is subject to the limitations associated with retrospective studies. All implantations were performed at a single center and therefore reproducibility may be limited and affected by institutional experience. The results of surgical studies are prone to 
learning curves and single center's specific characteristics. Moreover, the study period began 2 years ago; therapeutic strategies and increased clinical experience might have improved today's results.

Additionally, the number of patients on the new device was small, which reduces the statistical power. As such, larger studies need to be performed on the outcomes of patients with the HM3. Furthermore, this study is limited to a single LVAD and does not compare the outcomes of other comparable assist devices. Larger, prospective, randomized controlled studies might be useful to compare the long-term outcomes of different types of assist devices.

\section{CONCLUSIONS}

The novel LVAD HM3 has already shown good CE mark trial results. Within this first report on 6-month outcomes of a cohort, the survival after HM3 implantation was $85.2 \%$. The HM3 showed excellent midterm results with $0 \%$ stroke and $0 \%$ pump thrombosis rates 6 months after implantation.

\section{Conflict of Interest Statement}

Drs Haverich and Schmitto are consultants for Thoratec Cooperation. All other authors have nothing to disclose with regard to commercial support.

\section{References}

1. Thoratec Cooperation. 20,000 Reasons to believe. Available at: http:// heartmateii.com/. Accessed August 1, 2016.

2. Hanke JS, Rojas SV, Avsar M, Haverich A, Schmitto JD. Minimally-invasive LVAD implantation: state of the art. Curr Cardiol Rev. 2015;11:246-51.

3. Schmitto JD, Hanke JS, Rojas SV, Avsar M, Haverich A. First implantation in man of a new magnetically levitated left ventricular assist device (HeartMate III). J Heart Lung Transplant. 2015;34:858-60.

4. Netuka I, Sood P, Pya Y, Zimpfer D, Krabatsch T, Garbade J, et al. Fully magnet ically levitated left ventricular assist system for treating advanced HF: a multicenter study. J Am Coll Cardiol. 2015;66:2579-89.

5. Miller LW, Pagani FD, Russell SD, John R, Boyle AJ, Aaronson KD, et al. Use of a continuous-flow device in patients awaiting heart transplantation. $N$ Engl $J$ Med. 2007:357:885-96.

6. Slaughter MS, Rogers JG, Milano CA, Russell SD, Conte JV, Feldman D, et al. Advanced heart failure treated with continuous-flow left ventricular assist device. N Engl J Med. 2009;361:2241-51.

7. Schima H, Schlöglhofer T, Zu Dohna R, Drews T, Morshuis M, Roefe D, et al. Usability of ventricular assist devices in daily experience: a multicenter study. Artif Organs. 2014;38:751-60.

8. Rose EA, Gelijns AC, Moskowitz AJ, Heitjan DF, Stevenson LW, Dembitsky W, et al. Randomized Evaluation of Mechanical Assistance for the Treatment of Congestive Heart Failure (REMATCH) Study Group. Long-term use of a left ventricular assist device for end-stage heart failure. N Engl J Med. 2001;345:1435-43.
9. Strueber M, O’Driscoll G, Jansz P, Khaghani A, Levy WC, Wieselthaler GM. Multicenter evaluation of an intrapericardial left ventricular assist system. $J$ Am Coll Cardiol. 2011;57:1375-82.

10. Kirklin JK, Naftel DC, Pagani FD, Kormos RL, Myers S, Acker MA, et al. Pump thrombosis in the Thoratec HeartMate II device: an update analysis of the INTERMACS Registry. J Heart Lung Transplant. 2015;34:1515-26.

11. Mehra MR, Naka Y, Uriel N, Goldstein DJ, Cleveland JC Jr, Colombo PC, et al; MOMENTUM 3 Investigators. Fully magnetically levitated circulatory pump for advanced heart failure. N Engl J Med. 2017;376:440-50.

12. Starling RC, Moazami N, Silvestry SC, Ewald G, Rogers JG, Milano CA, et al. Unexpected abrupt increase in left ventricular assist device thrombosis. $N$ Engl J Med. 2014;370:33-40.

13. Schmitto JD, Avsar M, Haverich A. Increase in left ventricular assist device thrombosis. N Engl J Med. 2014;370:1463-4.

14. Smedira NG, Blackstone EH, Ehrlinger J, Thuita L, Pierce CD, Moazami N, et al. Current risks of HeartMate II pump thrombosis: non-parametric analysis of Interagency Registry for Mechanically Assisted Circulatory Support data. J Heart Lung Transplant. 2015;34:1527-34.

15. Haberl T, Riebandt J, Mahr S, Laufer G, Rajek A, Schima H, et al. Viennese approach to minimize the invasiveness of ventricular assist device implantation. Eur J Cardiothorac Surg. 2014;46:991-6.

16. Schmitto JD, Molitoris U, Haverich A, Strueber M. Implantation of a centrifugal pump as a left ventricular assist device through a novel, minimized approach: upper hemisternotomy combined with anterolateral thoracotomy. J Thorac Cardiovasc Surg. 2012;143:511-3.

17. Sileshi B, Haglund NA, Davis ME, Tricarico NM, Stulak JM, Khalpey Z, et al. In-hospital outcomes of a minimally invasive off-pump left thoracotomy approach using a centrifugal continuous-flow left ventricular assist device. $J$ Heart Lung Transplant. 2015;34:107-12.

18. Gregoric ID, Bruckner BA, Jacob L, Kar B, Cohn WE, La Francesca S, et al. Clinical experience with sternotomy versus subcostal approach for exchange of the HeartMate XVE to the HeartMate II ventricular assist device. Ann Thorac Surg. 2008;85:1646-9.

19. Anyanwu AC. Technique for less invasive implantation of Heartmate II left ventricular assist device without median sternotomy. Semin Thorac Cardiovasc Surg. 2011;23:241-4.

20. Samuels LE, Casanova-Ghosh E, Rodriguez R, Droogan C. Left ventricular assist device implantation in high risk destination therapy patients: an alternative surgical approach. J Cardiothorac Surg. 2012;7:21.

21. Hanke JS, Rojas SV, Martens A, Schmitto JD. Minimally invasive left ventricular assist device implantation with outflow graft anastomosis to the innominate artery. J Thorac Cardiovasc Surg. 2015;149:e69-70.

22. Rojas SV, Avsar M, Khalpey Z, Hanke JS, Haverich A, Schmitto JD. Minimally invasive off-pump left ventricular assist device exchange: anterolateral thoracotomy. Artif Organs. 2014;38:539-42.

23. Rojas SV, Haverich A, Schmitto JD. Off-pump versus on-pump left ventricular assist device exchange. Artif Organs. 2014;38:992.

24. Cheung A, Bashir J, Kaan A, Kealy J, Moss R, Shayan H. Minimally invasive, off-pump explant of a continuous-flow left ventricular assist device. J Heart Lung Transplant. 2010;29:808-10.

25. Schmitto JD, Rojas SV, Hanke JS, Avsar M, Haverich A. Minimally invasive left ventricular assist device explantation after cardiac recovery: surgical technical considerations. Artif Organs. 2014;38:507-10.

26. Hanke JS, Haverich A, Schmitto JD. Exchange of a HeartMate II left ventricular assist device with a HeartMate 3 pump. J Heart Lung Transplant. 2016;35 944-6.

Key Words: LVAD, Left ventricular assist device, HeartMate 3, outcomes, complications, survival 